\title{
Researching the Effects of Feedrate and Diamond Grain Size on Edge Chipping of Milled Granites
}

\author{
István Gábor GYURIKA
}

\begin{abstract}
Natural stones are common and preferred materials in the construction industry and in manufacturing technology, too. In every field of their application, it is outstandingly important that chipping caused by machining be minimised on the products' edges. The primary aim of this research was to examine chippings and damages at the edges of sample granite surfaces. The chippings and damages under scrutiny in this paper were caused by milling machining, and such machining was executed using different feedrate speeds and diverse diamond grain sizes. Within the scope of this paper, the results of the experiments were used to generate recommendations concerning the minimization of edge chipping. The results of the study show that the diamond grains' average size in the segments of the milling tools and the reduction of the applied feedrate obviously influences the magnitude of the rate of average edge chipping.
\end{abstract}

Keywords: diamond grain size; edge chipping; feedrate; granite; milling

\section{INTRODUCTION}

Natural stones - including granite, marble and limestone - are common and preferred materials in the construction industry, and have been increasingly used in recent years in manufacturing technology. In every field of their application, it is outstandingly important that chipping caused by machining be minimised on the products' edges. In the construction industry and in the case of home furniture pieces (for example kitchen counters, tables, etc.), considerable edge chipping can be especially unwanted for ergonomic reasons. On the other hand, in manufacturing technology, too extensive edge chipping can generate problems when it comes to the assembly of granite machine table and measuring machine table parts.

The primary aim of the research presented in this article was to examine chippings and damages at the edges of sample granite surfaces. The chippings and damages under scrutiny in this paper were caused by milling machining, and such machining was executed using different feedrate speeds and diverse diamond grain sizes. Within the scope of this paper, the results of the experiments were used to generate recommendations concerning the minimization of edge chipping. In the scope of the research, 36 sample surfaces were produced from 3 granite blocks with different average grain sizes. In the experiment, 3 tools with different diamond grain sizes were used and 4 different feedrates per tool were applied. The sample surfaces were prepared by an NC machining centre specialized for stone cutting. The rates of edge chipping on the sample surfaces were examined on the side where the machining tool exited the material. The measuring and digitalizing processes were executed using a Keyence type, blue light profile sensor. The edge chippings on the digitalized edge contour slices were evaluated with the help of a computer software application. The results of the study show that the diamond grains' average size in the segments of the milling tools obviously influences the magnitude of the rate of average edge chipping, while the reduction of the applied feedrate likewise manifestly decreases the rate of the average edge chipping up to the lower limit point. If a further reduction in technological parameters follows, this again generates an increase in the values of the edge chipping's quantitative marker.

The results of the experiment described in this article have proven appropriate for formulating recommendations concerning the minimization of the rate of edge chipping concerning milled granite edges. Furthermore, these results can also serve as a basis for future research.

\section{LITERATURE REVIEW}

Numerous studies in the field of the machining of natural stones deal with the efficiency of different cutting and milling tools as well as the effects of different geometries, material pairs and diverse components. Diamond tools with metal matrices are typical tools in automated stone machining. These devices, which exhibit continuous edges or segments, are generally applied for cutting granite, marble and limestone blocks, and are also used for milling plains, grooves, islands and pockets [1, 2]. Stone machining tools are typically characterised by the numbers of segments in the holder, the types of binder materials in the segments, and the average size of the diamond grains in the segments.

Minimising tool wear is one of the options of cost optimisation in the field of metal machining. This optimisation regime, however, cannot be used in the case of diamond cutting wheels or milling tools. Actually, machining using stone cutting and milling tools takes place by way of applying diamond grains on the surface of the matrix material, whereby grains get in contact with the workpiece, which results in the grains accomplishing the job of material removal. These diamond grains will do the machining job with proper efficiency so long as they do not wear out. A new diamond can take the job of worn-out grains only if the wheels concurrently exhibit appropriate rates of the matrix wear. Jerro et al. examined the wear processes of cutting wheels equipped with diamond segments in detail and drew conclusions concerning the effects of different manufacturing environments [3]. In the scope of his research, $\mathrm{Xu}$ also dealt with this topic in detail [4]. Moreover, several 
studies have been written worldwide that discuss the relationship between the wear processes of segments and machining forces acting during machining $[5,6,7,8]$.

In recent years, researchers have achieved significant results and advances in connection with the development of estimative systems. With the help of these systems, the rate of measurable forces acting during machining can efficiently be determined based on the applied technological parameters and features of the stone materials in question. In view of these interdependencies, specific estimative models were developed that can provide useful information concerning both technological parameters and the choice of machining tools. Turchetta et al. [9, 10, 11] developed a system comprising interdependent cutting relations with reference to the close vicinity of stone spots undergoing machining. As a result of this research, the distinct stages of the process of material removal became identifiable. Tanovic et al. [12] researched the features and optimal parameters of tools with diamond segments during micro machining processes. In the case of a mining drill system, Jiang et al. analysed pressure values applied during machining, and the effects of the intensity of cooling on cracks and breaks in natural stones [13]. Also in the case of mining-related machining, the damage processes of machined stone types were examined by Wang et al. [14], who used a finite element simulation method. Revealing results were published by Zhai et al. [15], who examined surface damaging and breaking effects of different frequency vibration waves in the case of granite materials.

Specific energy constitutes one of the main parameters with reference to the machining of natural stones [16]. The efficiency and the effectiveness of a machining process can efficiently be measured through determining specific energy. The determination of technological parameters (cutting speed, feedrate, cutting depth), with a view to minimizing specific energy in case of granite milling, is one of the most important trends of international research efforts [16, 17]. In the scope of their examination of the specific energy application of stone machining processes, $\mathrm{Xu}$ et al. considered the shape of the segments of the applied tools and the features of the grains of the segments [18]. Aydin et al. also studied the effects of diverse technological parameters [19]. In the scope of this latter study, microscopy results showed that the rate of the average surface roughness screened on the surface increases along with an increase in machining speed, as well as with an increase in cutting depth. Otherwise this roughness value will decrease parallel to an increase in coolant intensity.

In the field of polishing technology, several studies focus on the effects of size changes of diamond grains. Wang et al. [20] examined the effects of diamond grains of different polishing tools and the effects of diamond grains in the case of machining device tools, as well as studied the applied technological parameters in the scope of polishing granite surfaces. Research findings showed that the quality parameters of the examined surfaces progressively improved as the sizes of diamond grains used in polishing tools decreased [21]. With reference to polishing granite products, Huang et al. examined the relation between average surface roughness values and glossiness [22, 23].
Nevertheless, only a few studies have been written so far about edge chipping processes with reference to automated natural stone machining. In the scope of drilling stone materials, Mishnaevsky [24] researched the rate of resulting edge chipping. Furthermore, Guo et al. experimented with cutting tools and analysed the edge chipping of natural stones in different technological environments [25].

Gyurika et al. set up a complex quantitative system of markers and established an algorithm in order to examine the edge chipping processes in the case of milled granite surfaces [26, 27]. They also examined changes in the edge chipping of diverse milled granite edges that were produced using different cutting speeds.

\section{PRODUCTION OF MILLED SURFACES FOR RESEARCH}

For achieving the aims set out in the present study, the researchers produced 36 research sample surfaces from 3 types of granite. The production of these surfaces was effected using 3 tools and 4 different feedrates per tool. This section gives a detailed description of the characteristics of the selected granite materials, the main parameters of the tools applied and the machining features of the sample surfaces.

\subsection{Selected Granite Types}

For the purpose of the examinations, the selected types of granite cover the whole range of deep magmatic stones, including all categories of such stones, classified according to a standard reflecting average grain size. According to this standard, all granite types can be classified into 3 different categories (Table 1). The grain size of small grain stones is under $1 \mathrm{~mm}$. Middle size grain granites have an average grain size of 1 to $5 \mathrm{~mm}$. The category of large grain stones includes granites with grains of an average size above $5 \mathrm{~mm}$.

Table 1 Standard of average grain size of granites

\begin{tabular}{|c|c|}
\hline Average grain size & Stone-groups \\
\hline$d>5 \mathrm{~mm}$ & Large grain-size group \\
\hline $1 \mathrm{~mm} \leq d \leq 5 \mathrm{~mm}$ & Middle grain-size group \\
\hline$d<5 \mathrm{~mm}$ & Small grain-size group \\
\hline
\end{tabular}

In what follows, the characteristics of the selected granite materials are described. Granite No. 1 comes from Brazil; its commercial name is Giallo Farfalla. Giallo Farfalla is a deep magmatic stone: it is large-grained, tawny-coloured with a grey tone, its texture is crystallic and it is packed in structure. It is a large-grain granite with a slightly directional grit. Its typical elements include grand knotted, off-white quartz and k-feldspar. The porosity of this stone is intra-grain, and is under 5 volume percent. Stone No. 2 belongs to the middle grain category, it is called Rosa Beta and it originates from Italy. This granite is commercially available. It is a deep magmatic clear grey stone with a pink tone and a packed structured. Its stone texture is omnidirectional and crystallic grained. The main elements of the stone are knotted quartz and kfeldspar. The average size of the quartz grains is $1 \mathrm{~mm}$, but the biggest grains might reach a size of $2 \mathrm{~mm}$. The colour of this stone is due to the pink and white k- 
feldspar, which exhibit tabular development, and the grain size of this stone is over $2 \mathrm{~mm}$. The commercial name of granite No. 3 is Gabbro. It is grey in colour, the stone is dark-toned, it is a deep magmatic stone with a crystallic grit. The stone has a packed, homogeneous structure. Its main elements include knotted quartz and k-feldspar. The grain size of the knotted, off-white, isometric quartz is between 1 and $2 \mathrm{~mm}$, the quartz is situated in knots and is scattered in the stone texture. The prime elements of this stone are the greyish-white coloured, small grained, tubular progressed, twin structured orthoclases. Besides kfeldspar, plagioclases also appear in the stone, and these are small-grained, tubularly developed, and their sizes are under millimetre. Some other stone elements also appear in this stone but these exhibit different colours. The grain size of this stone is under one millimetre.

\subsection{Applied Milling Tools}

All of the applied tools were face milling tools with a $100 \mathrm{~mm}$ diameter and 22 segments. As a first step, for the preparation of the actual tools, models were developed at the Department of Manufacturing Science and Engineering of Budapest University of Technology and Economics. The next step was the brazing of segments to the model, and for this a cobalt-based binding agent was used. This job was performed at the premises of the Budapest-based Woldem Kft.

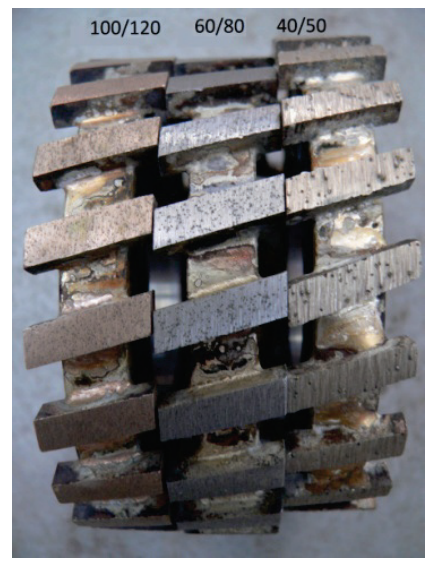

Figure 1 Applied milling tools

Diamond grain sizes in the segments were selected with a view to receiving a clear picture of the effects of edge chippings caused by changes in grain size. In the case of milling tools with segments, grain size can be determined using strainer numbers. The diamond grains to be used for these segments are sieved out of the strainer through applying different hole densities in order to achieve the most homogenous possible diamond grain sizes in the case of the applied tools. Actually, strainer numbers provide information about piles per inch $(25.4$ $\mathrm{mm}$ ) in the strainer: the bigger the number, the more densely piled the strainer is and the smaller the sieved grains are. Thus, strainer number is a quantitative marker and it consists of two values. The first value gives information about the density of the strainer's piles: in the case of this density, the diamonds still do pass through the strainer. The second value shows the upper limit of the density of the strainer's piles: in this case no diamond grains will fall through the strainer. The values of the strainer numbers of the tools applied in the scope of our research were 100/120,60/80, and 40/50 (Fig. 1).

\subsection{The Machining Process}

For the purpose of the study, sample granite surfaces were created using an NC controlled Italian Prussiani Golden Plus type machining tool, which has specifically been designed for drilling and stone milling. The machine tool is located at Woldem Kft.'s premise in Budapest. The size of the available granite blocks was $300 \times 300 \mathrm{mms}$, and on their surfaces 5 different sample surfaces per block were created using the above-specified NC controlled stone machining centre. The first step constituted of fixing the granite plate on the worktop (Fig. 2).

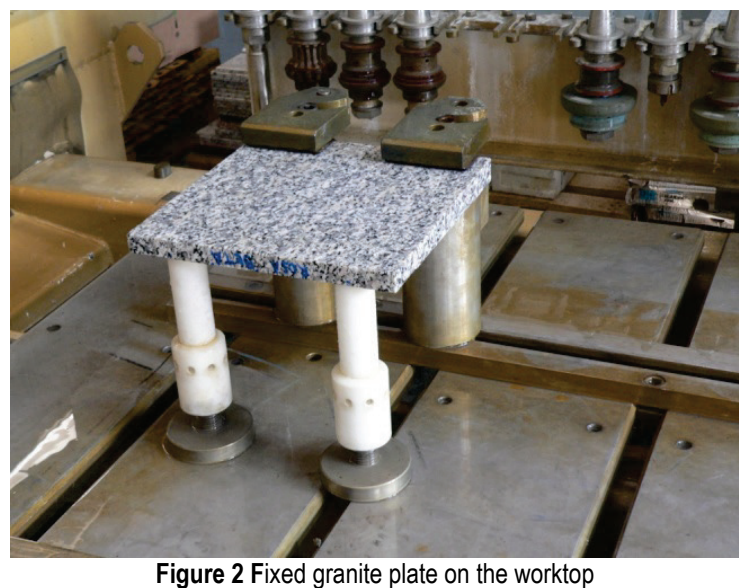

The device used for fixing the workpiece consisted of four elements. It consisted of two dog clutches, located outside the scope of the place of machining, on the side of the block. The other elements constituted of two lower fixing pieces, which not only provided the rigidity of the workpiece thanks to precise calibration, but they also set the workpiece parallel with the X-Y plains of the machining tool. After fixing, the next step was preliminary face-milling in order to equalize planar deflections. During the machining of the sample surfaces, $40 \mathrm{~mm}$ cutting width and $1 \mathrm{~mm}$ cutting depth were applied, and for this purpose up-cutting technology was used. Two blocks per granite type were prepared, and 12 sample surfaces were created using three different tools operating at four different feedrate values (Fig. 3). The applied feedrate values were: $200 \mathrm{~mm} / \mathrm{min}, 300 \mathrm{~mm} / \mathrm{min}$, $400 \mathrm{~mm} / \mathrm{min}$, and $500 \mathrm{~mm} / \mathrm{min}$, respectively; $1100 \mathrm{~m} / \mathrm{min}$ cutting speed was used during machining. In all cases, the sample surface to form was located $1 \mathrm{~mm}$ below the previous surface. This was necessary so as to avoid the tool potentially milling in the previous zone.

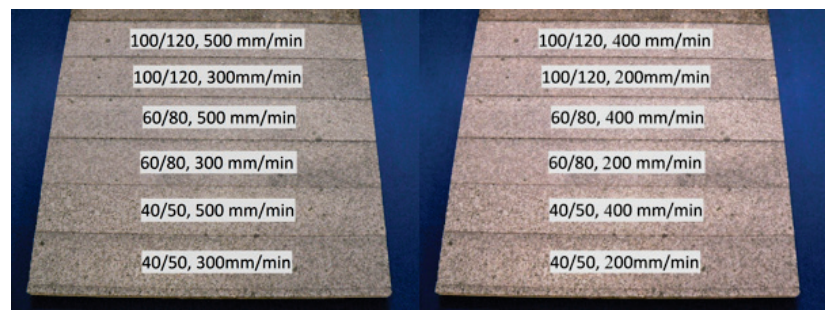

Figure 3 Sample surfaces of the granite blocks 
At the end of the machining process, 36 sample surfaces were produced, and it was concerning these surfaces that the examinations of the edges caused by the milling tools, on the side where the tools exited the material, were performed.

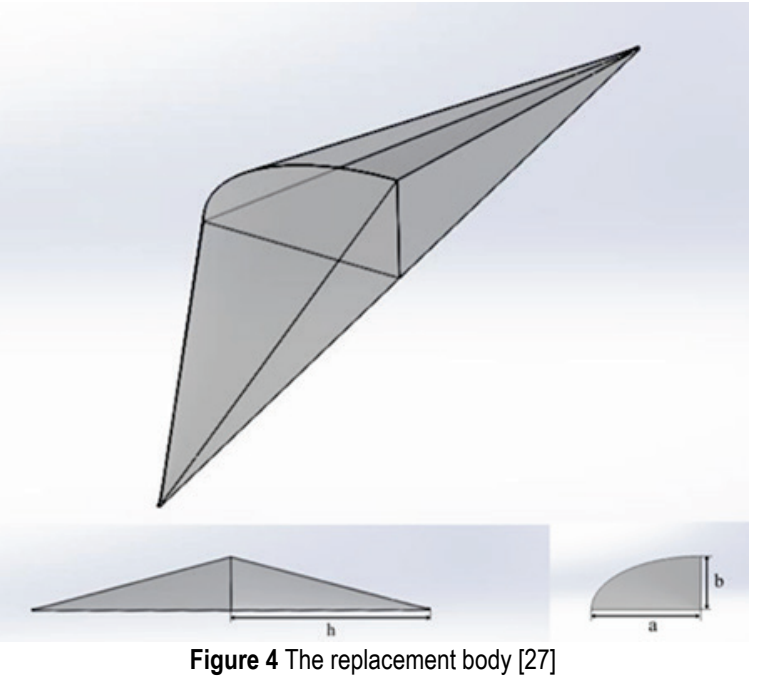

\section{EXAMINATION OF MILLED SURFACES}

Gyurika's notion of the "average edge chipping rate" [26] was used as a basis for the examination of the edge chipping of the sample surfaces. The quantitative marker of the average edge chipping rate, which is dimensionless and is based on specific volume loss, shows the average value of edge chipping concerning a given examination length. Furthermore, for the determination of the average edge chipping rate, a surrogate sample has to be used [27]. Because this surrogate sample is a complex body, the volume loss generated by the chippings can be defined with precision. This complex body consists of two quarter cones, adjacent to each other at their elliptical bases (Fig. 4). The distance between the original edge chipping's zero and endpoints (this will give the height of the twin cones), and the measurable maximal depths of edge chippings on the surface elements of the edges (these parameters will give the axes of the ellipsis) are necessary for the determination of the complex body's volume.

For the study of the edges of the sample surfaces thus produced, a complex measurement and evaluation system was developed. A Keyence L JV-7080 type, blue light profile sensor was included in the measurement and data collection process (Fig. 5). This unit features exceptional position precision: it has $10 \mu \mathrm{m}$ precision in the $\mathrm{X}$ direction, and $0.5 \mu \mathrm{m}$ in the $\mathrm{Z}$ direction. This precision range is afforded by the blue laser light used in the sensor: the wavelength of the blue laser light is between 420-490 $\mathrm{nm}$, as opposed to the universally used red light profile sensor, whose wavelength of red light is between 650-750 $\mathrm{nm}$. Because of their short wavelength, blue light profile sensors can achieve better position and repetition precision than red light profile sensors. Blue light scanners are capable of recording contour slices on limited distances and are capable of transferring measurement results to the database of the LI-Navigator 2 computer software accompanying the unit. In the course of the research, recording distance was defined as 0.1 $\mathrm{mm}$.

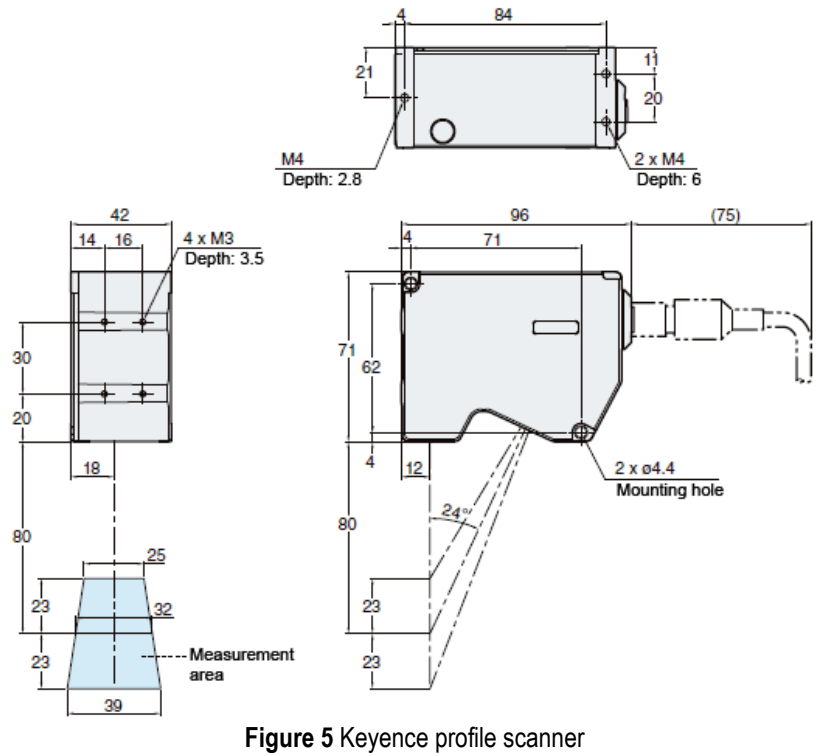

The blue light profile sensor was moved by a Topper TMV 510 type CNC machining centre. The size of the table of the machine tool was $600 \times 360 \mathrm{~mm}$; thus this size was suitable for placing the granite blocks. The dimensions of the machining centre's worktop were $510 \times$ $360 \times 300 \mathrm{~mm}$. The granite blocks were firmly fixed on the machining centre's worktop with the help of standard workpiece fixing devices. The studied edge was also set paralleled with the motion axis by way of using these devices. After that, the profile sensor was fixed on the side of the machining centre, which was followed by setting the scanning degree at $45^{\circ}$. The choice of this degree was important, because in the case of this setting no skewing of any kind appears with reference to recording the data of the contour slices.

After the digitalisation of the contour slices, the next step was the evaluation of the resulting edge chippings. The distance between the zero and endpoints of the edge chippings, and the maximum depth of the edge chippings measurable on the surfaces constituting the edges were automatically determined by the LI-Navigator 2 computer software. These parameters were used for defining the volume of the twin cones of replacement, which cones are in turn necessary for the determination of the value of the average edge chipping quantitative marker.

\section{RESULTS}

As a result of the measuring process, 36 sample surfaces cut from the three granite types were available for evaluation. In the evaluation phase, changes in edge chippings caused by the average size of the diamond grains in the segments of the tools were studied with reference to the different granite materials. The other objective of the research was to analyse the effects of changes in feedrate on average edge chipping rate. The evaluation was performed with the help of MiniTab 15 statistics software application.

After a closer examination of the diagrams and the ANOVA analysis has been performed, it can be stated 
that, according to the variance analysis, the significance coefficients in the case of all stones are so low that there is an obvious relationship between the change in the average edge chipping rate and the applied regression line assigned to this change by change of diamond grain sizes. In the case of stone No. 1 , this value is $P=0.015$, which means that there is only $1.5 \%$ likelihood that the regression line applied is not significant with respect to changes in average edge chipping rate. In the case of stone No. 2 the referent value is $P=0.024$, whereas in the case of stone No. 3 it is $P=0.053$.

Based on the ANOVA analysis of the measuring results shown on the diagrams, it can be stated that in the case of every stone the significance coefficient is so low that an obvious relationship between the changes of the average edge chipping rate and the applied regression line assigned to this change can be observed by change of feedrate. This value is the lowest and thus the least desirable in the case of stone No. 2, where it is $\mathrm{P}=0.018$. These values show that even in the case of the granite with the worst results there is only $1.8 \%$ likelihood that the regression line applied does not show a significant correlation with the change in the average edge chipping rate.
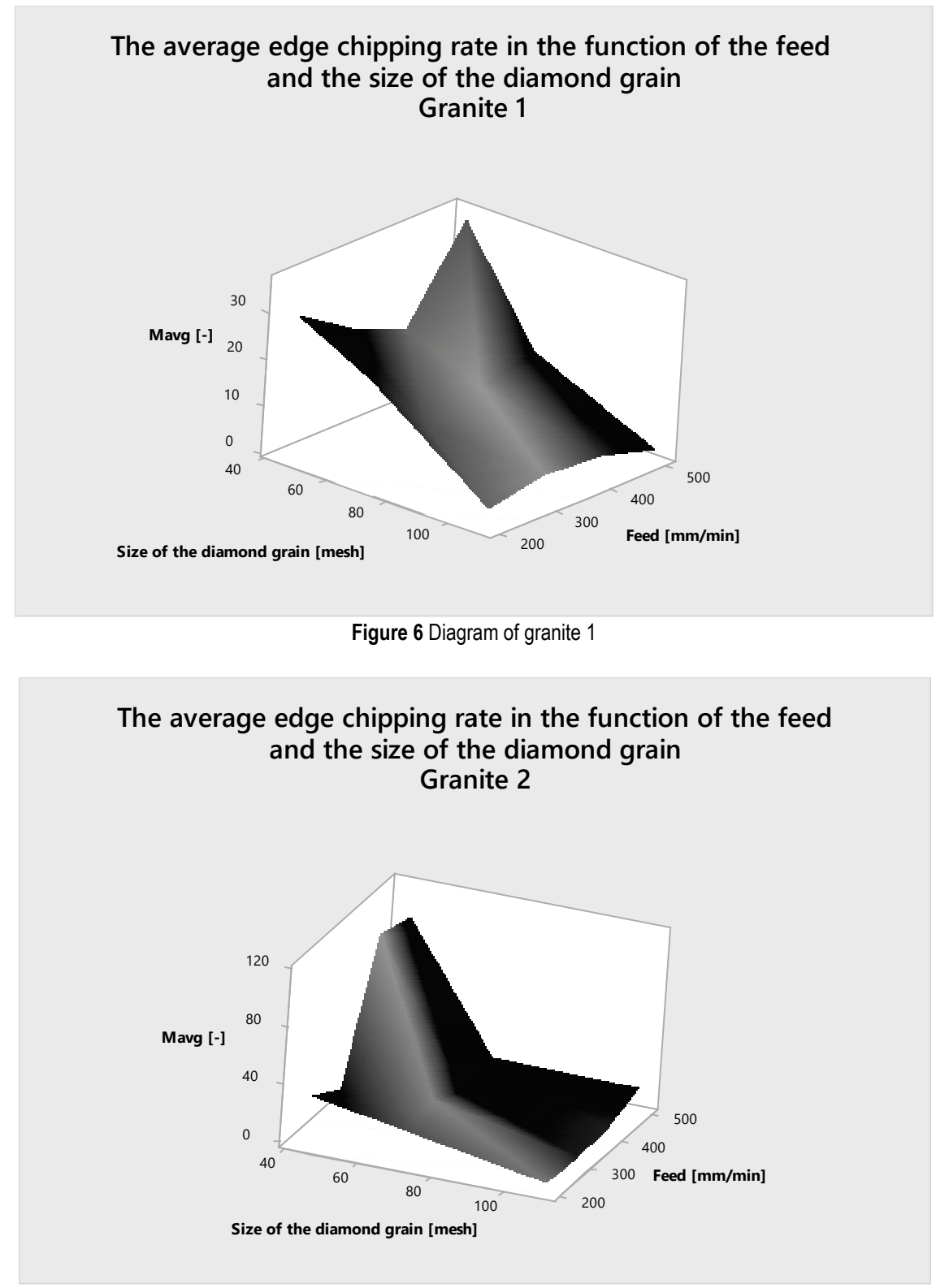

Figure 7 Diagram of granite 2

Figs. 6, 7 and 8 show changes in average edge chipping rates generated by the effects of increase in feedrate and by the effects of changes in the average size of diamond grains. In the case of the three stone types, it can be claimed, without doubt, that reduction in diamond grains in the segments of milling tools shows a monotonous and significant decrease in average edge chipping rates. The results of the examinations unquestionably prove that a reduction in the sizes of diamond grains decreases edge chipping in the case of milled granite surfaces. The primary reason for this trend is that a tool having larger particle sizes leaves deeper grooves on the workpiece surface. Larger, spaced grooves generate inferior surface quality. 


\section{The average edge chipping rate in the function of the feed and the size of the diamond grain Granite 3}

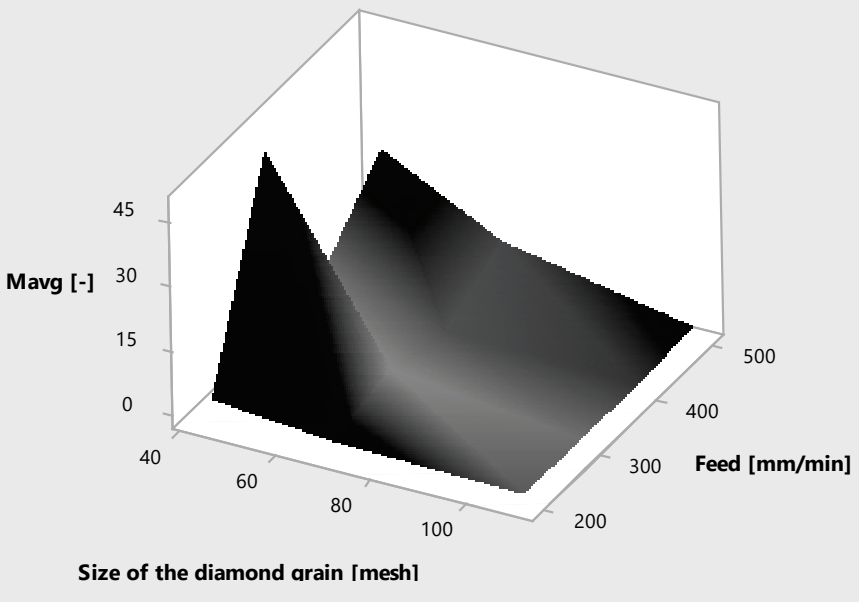

Figure 8 Diagram of granite 3

The diagrams also attest that, due to reductions in federate, average edge chipping decreases for a while, then - after having reached a low limit point - the rate increases anew. This tendency has been identified in the case of every stone type, but not at the same limit point. In the case of granite type No. 1 in the large grain granite category, this low limit point takes effect at a 400 $\mathrm{mm} / \mathrm{min}$ feedrate value, while in the case of smaller grain sizes the corresponding limit point is $300 \mathrm{~mm} / \mathrm{min}$, where a minimal edge chipping rate was calculated. Accordingly, it was determined that due to the effect of reductions in feedrate, average edge chipping rate in the case of milled granite edges shows a regressing tendency, which tendency, after reaching a low limit point, shows a sudden change and the corresponding value starts to increase. This change of tendency can be explained by changes in forces. What happens in this case is that the tool breaks off increasing amounts of granite grains rather than cutting through them due to increasingly smaller and smaller feedrates. As a result of this, deterioration of edge chipping resurfaces and appears again at low feedrate values.

\section{CONCLUSIONS}

The study described in this article examined changes of average diamond grain size in the segments of milling tools used in the milling process described above, and it also described in what ways feedrate applied during machining can influence edge chipping with respect to the edges of granite surfaces.

During the machining process, 12 sample surfaces were prepared from each of the 3 granite types using a CNC machining centre specialized for stone drilling and milling. In the case of each sample surface, 4 different feedrate values were applied using milling tools equipped with 3 different average grain sizes. In the scope of the measuring procedure, the contours of the edges were digitalized using a blue light profile sensor, and the edge chippings were evaluated by a computer software application.

On the basis of the evaluation of the research results, it can be stated that the average size of the diamond grains in the segments of the milling tools obviously influences the average edge chipping rate of granite edges. A general research result, in the case of all granite types, is that reductions in the size of the diamond grains generate a corresponding decrease in average edge chipping rates.

Furthermore, reduction in the feedrate exerts a quite complex effect on the edge chipping of granite edges: along with decreasing feedrates, the average edge chipping will decrease to the lower limit point, but any further decrease of the feedrate will increase the value of the quantitative marker of the average edge chipping rate. The diagrams clearly show that the lower limit point is situated at diverse places in the case of different stone types. Based on the formulation of a statement concerning the effects of reduction in feedrate, the author of the article urges future studies with a view to finding out what kind of parameters (for example, average grain size of granite materials, substance composition, the joint effects of these two, etc.) play a part in causing different lower limit points in the case of different types of granite.

On the basis of the research findings presented in this article, it can be claimed that well-grounded statements can be formulated concerning the edges of milled granite surfaces, the average sizes of diamond grains in milling tools, and the changes caused by reductions in applied feedrates.

\section{Acknowledgements}

I wish to express my gratitude to teaching assistant Anna Ferenczy at the Department of Manufacturing Science and Engineering of Budapest University of Technology and Economics for her help with the measurement and evaluation process. I am also grateful to Technical Manager of Woldem Kft. István Gyurós for his 
co-operation and support concerning the execution of milling jobs.

We acknowledge the financial support of Széchenyi 2020 under the EFOP-3.6.1-16-2016-00015.

\section{REFERENCES}

[1] Tönshof, H. K., Hillmann-Apmann, H., \& Asche, J. (2002). Diamond tools in stone and civil engineering industry: cutting principles, wear and applications. Diamond and Related Materials, 11(3-6), 736-741. https://doi.org/10.1016/s0925-9635(01)00561-1

[2] Webb, S. W. (1999). Diamond retention in sintered cobalt bonds for stone cutting and drilling. Diamond and Related Materials, 8(11), 2043-2052. https://doi.org/10.1016/s0925-9635(99)00167-3

[3] Jerro, H. D., Pang, S. S., Yang, C., \& Mirshams, R. A. (1999). Kinematics analysis of the chipping process using the circular diamond saw blade. Journal of Manufacturing Science and Engineering, 121(2), 257-265. https://doi.org/10.1115/1.2831214

[4] Xipeng, X. (2000). Prevailing mechanisms for circular sawing of granites with diamond impregnated segments. Materials and Manufacturing Processes, 15(1), 123-138. https://doi.org/10.1080/10426910008912977

[5] Yilmaz, N. G., Goktan, R. M., Gasan, H., \& Celik, O. N. (2013). Particle size distribution and shape characterization of the chips produced during granite machining in relation process forces and specific energy. Particulate Science and Technology, 31(3), 277-286. https://doi.org/10.1080/02726351.2012.726943

[6] Zhang, J. S., Zhang, Z. M., Ding, M. W., Wang, H. C., \& Wang, Z. (2013). Experimental study on fractal laws of cutting focre for machining irregular surface of granite. Advances in Abrasive Technology, 793, 214-219. https://doi.org/10.4028/www.scientific.net/amr.797.214

[7] Zhang, Z. M., Xiao, H. W., Wang, G. Z., Zhang, S. Z., \& Zhang, S. Q. (2013). Modeling and experimental study on cutting force of diamond circular saw in cutting granite using response surface methodology. Advances in Materials and Materials Processing 652-654, 2191-2195. https://doi.org/10.4028/www.scientific.net/amr.652-654.2191

[8] Bíró, I., Czampa, M., \& Szalay, T. (2015). Experimental model for the main cutting force in face milling of a high strength structural steel. Periodica Polytechnica Mechanical Engineering, 59(1), 16-22. https://doi.org/10.3311/ppme.7516

[9] Turchetta, S. (2009). Cutting force on a diamond grit in stone machining. International Journal of Advanced Manufacturing Technology, 44(9-10), 854-861. https://doi.org/10.1007/s00170-008-1905-7

[10] Turchetta, S. (2010). Cutting force in stone machining by diamond disk. Advances in Materials Science and Engineering 2010, 1-6. https://doi.org/10.1155/2010/631437

[11] Turchetta, S. \& Polini, W. (2011). Cutting force in stone lapping. International Journal of Advanced Manufacturing Technology 57(5-8), (2011), 533-539. https://doi.org/10.1007/s00170-011-3311-9

[12] Tanovic, L., Bojanic, P., Puzovic, R., \& Milutinovic, M. (2011). Experimental investigation of microcutting mechanisms in granite grinding. Journal of Manufacturing Science and Engineering, 133(2), 024501, https://doi.org/10.1115/1.4003521

[13] Jiang, H., Du, C., Zheng, K., \& Liu, S. (2015) Experimental Research on the rock fragmentation loads of a water jet-assisted cutting head. Technical Gazette, 22(5), 1277-1285. https://doi.org/10.17559/tv-20141020152601

[14] Wang, S., Li, N., Li, C., \& Cao, C. (2015). Distribution characteristics analysis on pressure-arch in horizontal stratified rocks under coal mining conditions. Technical Gazette, 22(4), 997-1004. https://doi.org/10.17559/tv-20141207160855

[15] Zhai, Y., Li, N., Wang, S., \& Zhang, Y. (2015). Space wave equation considering damage-induced weakening and strain rate dependency of rock. Technical Gazette, 22(4), 10351042. https://doi.org/10.17559/tv-20150406112756

[16] Buyuksagis, I. S. (2007). Effect of cutting mode on the sawability of granites using segmented circular diamond sawblade. Journal of Materials Processing Technology, 183(2-3), 399-406 https://doi.org/10.1016/j.jmatprotec.2006.10.034

[17] Ersoy, A. \& Atici, U. (2004). Performance characteristics of circular diamond saws in cutting different types of rocks. Diamond Related Materials, 13(1), 22-37. https://doi.org/10.1016/j.diamond.2003.08.016

[18] Xu, X. P. \& Huang, H. (2004). High-efficiency cutting of granite blocks with multi-blade diamond saws. Advances in Abrasive Technology, 257-258, 297-302. https://doi.org/10.4028/www.scientific.net/kem.257-258.297

[19] Aydin, G., Karakurt, I., \& Aydiner, K. (2013). Investigation of the surface roughness of rocks sawn by diamond sawblades. International of Rock Mechanics and Mining Sciences, 61, 171-182. https://doi.org/10.1016/j.jijmms.2013.03.002

[20] Wang, D., Chen, X., Oeser, M., Stanjek, H., \& Steinauer, B. (2014). Study of micro-texture and skid resistance change of granite slabs during the polishing with the Aachen Polishing Machine. Wear, 318(1-2), 1-11. https://doi.org/10.1016/j.wear.2014.06.005

[21] Yavuz, H., Ozkahraman, T., \& Demirdag, S. (2011). Polishing experiments on surface quality of building stone tiles. Construction and Building Materials, 25(4), 17071711. https://doi.org/10.1016/j.conbuildmat.2010.10.016

[22] Huang, H., Li, Y., Shen, J. Y., Zhu, H. M., \& Yu, X. P. (2002). Micro-strucutre detection of a glossy granite surface machined by the grinding process. Journal of Materials Processing Technology, 129(1-3), 403-407. https://doi.org/10.1016/s0924-0136(02)00702-1

[23] Huang, H. \& Xu, X. P. (2004). Interfacial interactions between diamond disk and granite during vertical spindle grinding. Wear, 256(6), 623-629. https://doi.org/10.1016/j.wear.2003.10.005

[24] Mishnaevsky, L. L. (1996). Physical mechanisms of hard rock fragmentation under mechanical loading: a review. International Journal of Rock Mechanics and Mining Sciences, 33(4), 763-766. https://doi.org/10.1016/0148-9062(96)85006-6

[25] Guo, H., Aziz, N. I., \& Schmidt, L. C. (1992). Rock cutting study using linear elastic fracture mechanics. Engineering Fracture Mechanics, 41(5), 771-778. https://doi.org/10.1016/0013-7944(92)90159-c

[26] Gálos, M. \& Gyurika, I. G. (2014). Quality measuring numbers of milled edges of granite surfaces. Periodica Polytechnica Civil Engineering, 58(2), 121-129. https://doi.org/10.3311/ppci.2158

[27] Gyurika, I. G. \& Szalay, T. (2015). Examination of the average chipping rate on the edges of milled granite surfaces.Measurement Science Review, 15(1), 1-8. https://doi.org/10.1515/msr-2015-0001

\section{Contact information}

István Gábor GYURIKA, PhD, Associate Professor University of Pannonia,

Institute of Mechanical Engineering, Department of Mechanics

Egyetem Street 10., H-8200 Veszprém, Hungary

E-mail: gyurika@almos.uni-pannon.hu

E-mail: gyurika@manuf.bme.hu 